\title{
PROPOFOL REMIFENTANIL DEEP SEDATION FOR GASTROINTESTINAL ENDOSCOPY IN CHILDREN
}

Ibrahim Abu-Shahwan MD, John Thornton MBBCh, Khalid Chowdary MD, Uwe Schwarz MD, Kimmo Murto MD. Department of Anesthesiology, Children Hospital of Eastern Ontario, 401 Smyth Rd, University of Ottawa, Ottawa, Ontario K1H 8L1

INTRODUCTION: Gastrointestinal flexible endoscopy has become an important diagnostic and therapeutic procedure in children. In many medical centers, the use of general anesthesia for upper and lower gastrointestinal endoscopy has been replaced by intravenous sedation (1). Limited data are available on the use of propofol remifentanil sedation in children $(2,3)$. The aim of our study was to evaluate the safety and efficacy of remifentanil propofol combination for deep sedation in children undergoing gastrointestinal endoscopy.

METHODS: After ethics committee approval we evaluated the safety and efficacy of a combination of propofol and remifentanil sedation in 30 children, 1 to 7 years of age, ASA I-III, undergoing elective upper and/or lower gastrointestinal endoscopy. Inhalation induction was with sevoflurane, nitrous, and oxygen and discontinued once the intravenous line was in place. Remifentanil infusion $0.1 \mathrm{mcg} / \mathrm{kg} / \mathrm{min}$ and propofol $1 \mathrm{mg} / \mathrm{kg}$ bolus followed by propofol infusion of $80 \mathrm{mcg} / \mathrm{kg} / \mathrm{min}$ were used for sedation. The propofol infusion was decreased to 50 $\mathrm{mcg} / \mathrm{kg} / \mathrm{min} 10$ minutes after the start of the procedure. The remifentanil infusion was decreased to $0.05 \mathrm{mcg} / \mathrm{kg} / \mathrm{min}$ when the procedure lasted more than 30 minutes. The children were kept spontaneously breathing with nasal pronge at 3-5 1/min. Hemoglobin oxygen saturation, respiratory rate, blood pressure, and heart rate were monitored continuously and recorded at 5min intervals.

RESULTS: Thirty children completed the study. Hemodynamic stability was maintained in all children throughout the procedure and no case of respiratory depression was observed. In one child, a single dose of propofol $1 \mathrm{mg} / \mathrm{kg}$ was given due to excessive movements. All children had their eyes open within 5 min after discontinuing drugs infusion. No complications were recorded during the procedure or in the recovery period. The conditions to perform the procedures were considered excellent by our gastroenterologists.

DISCUSSION: Based on the result of our study, deep sedation with a combination of propofol and remifentanil in small children can be successfully performed without adverse effects.

\section{References:}

1- NEJM 2000; 342: 938-945

2- BJA 1998; 80: 509-511

3- Ped Anesth 2000; 10: 59-63 